\title{
Hemorragia pulmonar, una complicación poco frecuente en una niña con púrpura de Schönlein-Henoch
}

\author{
Pulmonary hemorrhage, a rare complication in a girl with Henoch-Schönlein \\ purpura
}

Dra. Gokce Gur , Profesora Titular Dra. Nilgun Cakar, ${ }^{a, b}$, Dra. Saba Kiremitcic, Dra. Aysel Taktak, Dra. Ozge Basaran ${ }^{b}$ y Dra. Nermin Uncu ${ }^{a, b}$

\begin{abstract}
RESUMEN
La púrpura de Schönlein-Henoch (PSH) es la vasculitis más frecuente en los niños. Los procesos vasculíticos pueden afectar el pulmón. Si bien la hemorragia alveolar difusa puede considerarse una de las manifestaciones de la PSH, no es un cuadro frecuente. En este artículo presentamos el caso de una niña de 10 años con nefritis por PSH que sufrió hemorragia pulmonar. La paciente recibió un tratamiento satisfactorio con metilprednisolona intravenosa. La revisión de las publicaciones reveló que la edad temprana puede influir de manera positiva en el pronóstico, y que los inmunosupresores y el tratamiento complementario son fundamentales.

Palabras clave: púrpurade Schönlein-Henoch, hemorragiaalveolar, pulmonar, niño.
\end{abstract}

http:/ /dx.doi.org/10.5546/aap.2016.e366

\section{INTRODUCCIÓN}

La púrpura de Schönlein-Henoch (PSH) se caracteriza por la presencia de púrpura no trombocitopénica en las extremidades inferiores, dolor abdominal, compromiso renal, histopatología típica, artritis y artralgia. ${ }^{1}$ Es la vasculitis más frecuente en los niños. El compromiso pulmonar es poco frecuente y aumenta de forma significativa la mortalidad. ${ }^{2}$ Existen pocos informes acerca de la hemorragia pulmonar en la PSH.

a. Departamento de Nefrología Pediátrica, Hospital Pediátrico de Educación e Investigación sobre Hematoncología de Ankara, Turquía

b. Departamento de Reumatología Pediátrica, Hospital Pediátrico de Educación e Investigación sobre Hematoncología de Ankara, Turquía

c. Departamento de Patología, Escuela de Medicina de Ankara, Ankara, Turquía.

Correspondencia:

Dra. Ozge Basaran: ozgesalor@yahoo.com

Financiamiento: Ninguno.

Conflicto de intereses: Ninguno.

Recibido: 20-2-2016

Aceptado: 25-4-2016

\section{PRESENTACIÓN DE UN CASO}

Una niña de 10 años acudió a consulta por erupción purpúrica en la superficie extensora de las extremidades inferiores y superiores. Dos días después, presentó dolor abdominal y edema periorbitario. Sus antecedentes personales y familiares no presentaban particularidades. El cuadro clínico inicial indicaba que la paciente tenía un peso de $29 \mathrm{~kg}$, signos vitales normales, presión arterial de 130/80 mmHg, erupción purpúrica en la superficie extensora de los miembros y edema periorbitario; el resto del examen clínico fue normal.

Los análisis de laboratorio mostraron: hemoglobina 10,9 $\mathrm{g} / \mathrm{dl}$, plaquetas $365000 / \mathrm{mm}^{3}$, leucocitos $10900 / \mathrm{mm}^{3}$, tiempo de protrombina 14 $\mathrm{s}$, tiempo de tromboplastina parcial activada $28 \mathrm{~s}$, sodio sérico $134 \mathrm{mmol} / \mathrm{L}$, potasio $5 \mathrm{mmol} / \mathrm{L}$, urea $110 \mathrm{mg} / \mathrm{dl}$ y creatinina $0,93 \mathrm{mg} / \mathrm{dl}$. La proteína total fue de 5,0 g/dl, y la albúmina, de 2,3 g/ dl; los valores de AST y ALT fueron normales. Los resultados del análisis de sangre oculta en heces fueron negativos. Los niveles de IgA, IgG e IgM estuvieron dentro de los intervalos normales; las pruebas del antígeno de superficie de la hepatitis B (HBsAg), de anticuerpos contra el VHC (anti-HCV $\mathrm{Ab}$ ), anticuerpos antinucleares (ANA), anticuerpos contra el ADN bicatenario (anti dsDNA) y anticuerpos anticitoplasma de neutrófilos (ANCA) fueron negativas; la prueba de anticuerpos de superficie de la hepatitis $B$ (anti-HBs Ab) fue positiva. El título de antiestreptolisina $\mathrm{O}$ (ASO) fue de 135 U. El análisis de orina mostró: proteínas 4+, eritrocitos $>45$ por campo de gran aumento (HPF) y leucocitos de 15 a 20 por HPF. La proteinuria fue de $204 \mathrm{mg} / \mathrm{m}^{2} /$ hora.

Se tomó una biopsia de riñón, cuyo examen histopatológico reveló glomerulonefritis proliferativa difusa con hipercelularidad endocapilar, proliferación mesangial extensa y proliferación extracapilar focal con medialunas celulares. En algunos glomérulos, se observó exudado leucocitario y cariorrexis. Los depósitos hialinos en la membrana basal glomerular 
(MBG) periférica similares a la clásica lesión en asa de alambre de la nefritis lúpica eran notables y representaban la acumulación masiva de inmunocomplejos (Figura 1a). Conforme a este hallazgo histológico, la microscopia de inmunofluorescencia reveló depósitos difusos de IgG, IgA y C3 en la MBG periférica, y depósitos menos intensos de $\mathrm{C} 1 \mathrm{q}$ y fibrinógeno en el mesangio y la MBG. También se identificaron depósitos de IgG en el mesangio (Figura 1b). La biopsia se informó con un diagnóstico descriptivo de "glomerulonefritis proliferativa con proliferación endocapilar difusa y extracapilar focal", con un comentario que indicaba características patológicas similares a la glomerulonefritis membranoproliferativa (GNMP). Ante la ausencia de indicadores serológicos de lupus y el cuadro clínico integral de PSH, se interpretó como un subtipo proliferativo difuso de nefritis por PSH. De acuerdo con los resultados histopatológicos, se inició un tratamiento que incluía metilprednisolona en pulsos intravenosos $(30 \mathrm{mg} / \mathrm{kg} /$ día $)$ durante 3 días seguida de $2 \mathrm{mg} / \mathrm{kg}$ / día de prednisolona oral, $2 \mathrm{mg} / \mathrm{kg} /$ día de ciclofosfamida oral, $5 \mathrm{mg} /$ $\mathrm{kg} /$ día de ácido acetilsalicílico, $5 \mathrm{mg} / \mathrm{kg} /$ día de dipiridamol y $0,05 \mathrm{mg} / \mathrm{kg} /$ día de enalapril.

La paciente reingresó por fiebre tres semanas después de recibir el alta. El examen físico reveló lo siguiente: temperatura corporal de $38^{\circ} \mathrm{C}$, pulso de 120 lpm y presión arterial de 85/55 mmHg; además, la paciente tenía aspecto pálido y débil. Se hallaron estos valores: $\mathrm{Hb} 7,3 \mathrm{~g} / \mathrm{dl}$, plaquetas $291000 / \mathrm{mm}^{3}$, leucocitos $1700 / \mathrm{mm}^{3}$, urea $48 \mathrm{mg} /$ dl y creatinina $0,8 \mathrm{mg} / \mathrm{dl}$. El tratamiento con ciclofosfamida se interrumpió el día 52 debido a la reducción en el recuento de leucocitos, y se inició tratamiento con cefotaxima y amikacina. $\mathrm{Al}$ quinto día de tratamiento antibiótico, la paciente presentó dificultad respiratoria, taquipnea y taquicardia. La saturación de oxígeno fue del $70 \%$, y el análisis de gases en sangre arterial mostró hipoxemia. El nivel de dímero D fue normal. La radiografía de tórax mostró infiltrados pulmonares difusos (Figura 2) y la TC de tórax amplias áreas de atelectasia, densidades reticulares nodulares y áreas de opacidad en vidrio esmerilado. La electrocardiografía reveló taquicardia sinusal y la ecocardiografía mostró insuficiencia mitral leve relacionada con la taquicardia; las funciones sistólicas y diastólicas, y la arteria pulmonar y sus ramas se veían normales.

Se consideró el diagnóstico de compromiso pulmonar por hemorragia alveolar difusa debido a la caída repentina de la hemoglobina y la aparición de nuevos infiltrados pulmonares, con ausencia de cardiopatía, valores de dímero D y presión arterial pulmonar normales, falta de proliferación en el medio de cultivo y análisis de laboratorio con resultados negativos para el virus

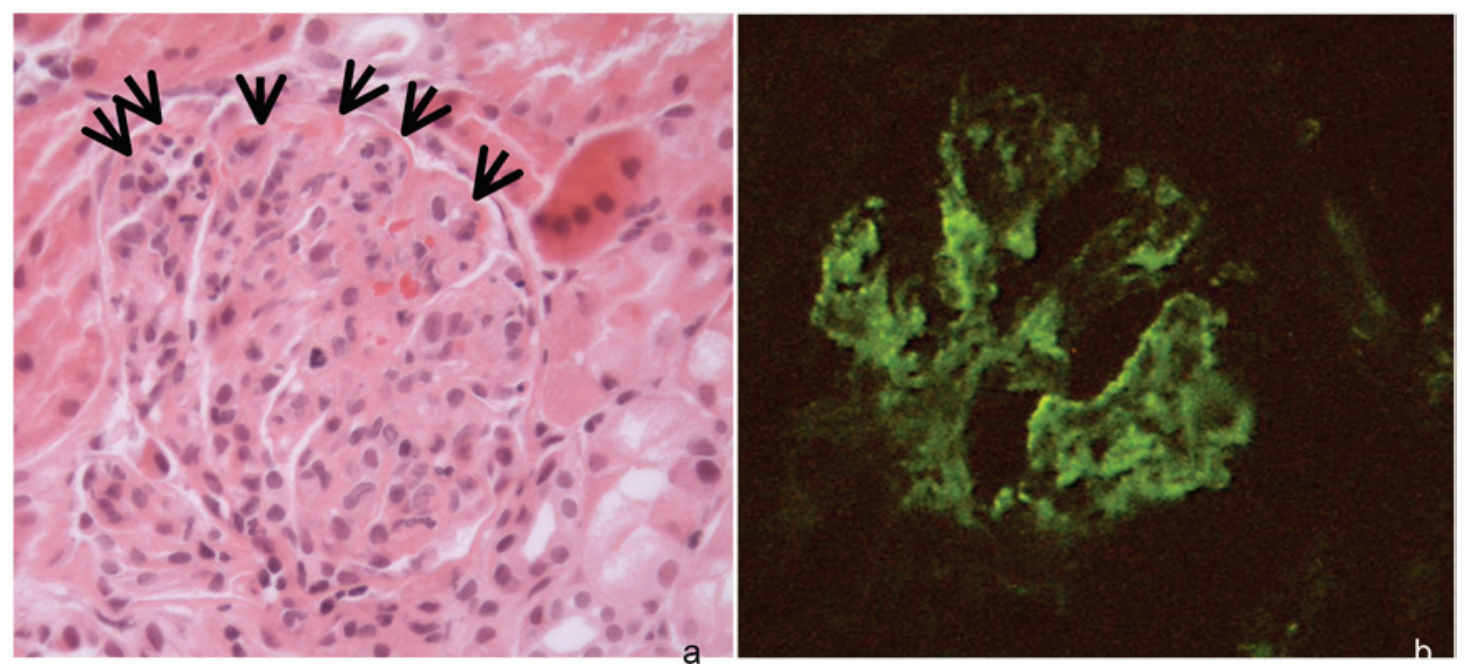

a. Los glomérulos hiperlobulares revelan una extensa proliferación mesangial y endocapilar. Los depósitos hialinos en la MBG periférica (observados como material eosinófilo) indican la acumulación de inmunocomplejos (flechas). Tinción con hematoxilina y eosina $\mathrm{x} 200$.

b. Se observan depósitos de IgG tanto en la MBG periférica como en el mesangio a través de la microscopia de inmunofluorescencia. IFMx200.

MBG: membrana basal glomerular. 
de Epstein B y el parvovirus B.

Se administró metilprednisolona en pulsos (30 mg/kg/día) durante 3 días. Las manifestaciones clínicas y los infiltrados pulmonares mostraron una rápida recuperación 12 horas después de la primera dosis de MP en pulsos. El tratamiento continuó con $2 \mathrm{mg} / \mathrm{kg} /$ día de prednisolona oral durante un mes, y las dosis diarias fueron disminuyendo en los meses posteriores. El tratamiento de tres días con MP en pulsos se repitió cada cuatro semanas durante seis meses. Debido a que las dosis acumuladas de ciclofosfamida alcanzaron los $150 \mathrm{mg} / \mathrm{kg}$, no se reanudó el tratamiento.

Al final de los seis meses de tratamiento con MP en pulsos, los valores de presión arterial, hemoglobina, análisis de orina y análisis de creatinina, urea y albúmina séricas fueron todos normales.

\section{DISCUSIÓN}

La púrpura de Schönlein-Henoch es la vasculitis más frecuente en los niños. La afectación cutánea es evidente en todos los pacientes. La incidencia de compromiso articular es del $82 \%$; se observa compromiso gastrointestinal en el $50 \%$ al $75 \%$ de los casos; compromiso renal en el $20 \%$ al $60 \%$ de los casos; y compromiso urogenital, neurológico y pulmonar en el 27\%, 2\% y 1\% de los casos, respectivamente. ${ }^{1,2}$
Los informes previos de compromiso pulmonar en la PSH han incluido vasculitis / capilaritis, hemorragia alveolar difusa (HAD) y fibrosis intersticial. Además, en los pacientes con $\mathrm{PSH}$, se ha observado una disminución aislada en la capacidad de difusión del monóxido de carbono en combinación con signos radiológicos sutiles de compromiso pulmonar intersticial en ausencia de síntomas pulmonares. ${ }^{3}$

La hemorragia alveolar difusa es una complicación poco frecuente de la PSH, y los datos sobre la frecuencia, el tratamiento y los resultados son escasos.

De acuerdo con la clasificación EULAR/ PRINTO/PRES de Angora 2008 para la PSH, se considera hemorragia alveolar cuando se documentan al menos dos de los siguientes resultados: caída de la hemoglobina, hemoptisis, nuevos infiltrados pulmonares, macrófagos cargados de hemosiderina en el líquido de lavado broncoalveolar, o piezas quirúrgicas o de autopsia que revelan hemorragia alveolar con o sin vasculitis leucocitoclástica. ${ }^{1}$

La hemorragia alveolar difusa se manifiesta a través de signos y problemas sistémicos (debilidad, fiebre, pérdida de peso, dolor articular, erupción cutánea); depósitos de eritrocitos intra-alveolares debido a los inmunocomplejos circulantes y la ruptura de la membrana alveolo-capilar, e insuficiencia respiratoria hipoxémica, hemoptisis

FIgURA 2. Tomografías computadas del tórax
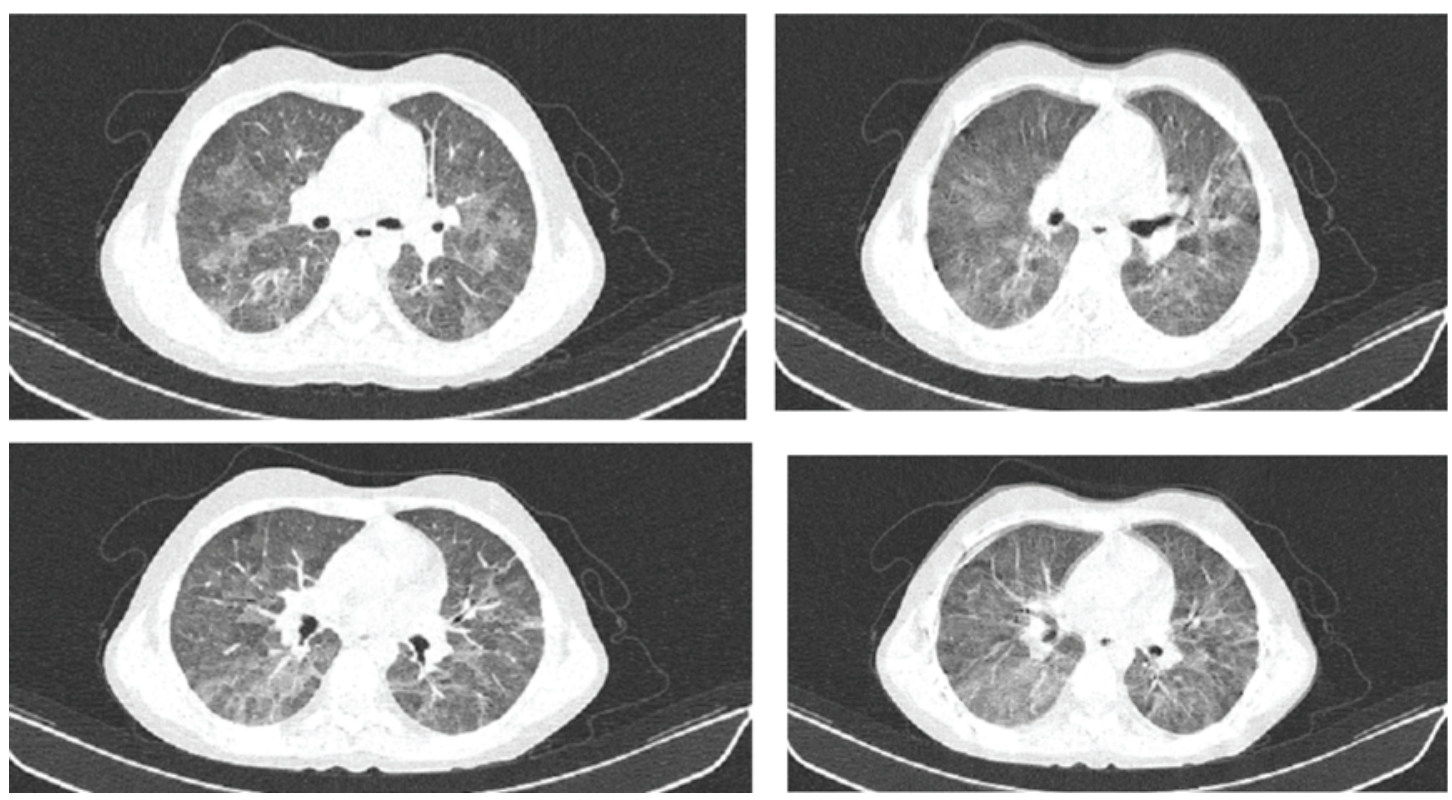

Se observan densidades reticulares y opacidades parcheadas en vidrio esmerilado. 
y anemia asociadas; y áreas de infiltrados pulmonares, focales o generalizados en los estudios por imágenes. ${ }^{4}$

No se ha establecido el tratamiento estándar para la hemorragia pulmonar asociada con la PSH, pero la mayoría de los informes previos ${ }^{1,5,6}$ sugieren que el uso activo de corticoesteroides (prednisona oral o metilprednisolona en pulsos) e inmunosupresores (ciclofosfamida, azatioprina y ciclosporina A) puede reducir notablemente la tasa de mortalidad. . $, 5,7,8$ Chen y col. realizaron el resumen de la bibliografía sobre pacientes pediátricos con hemorragia pulmonar asociada con la PSH. Informaron que todos los pacientes sin insuficiencia respiratoria sobrevivieron después de haber recibido tratamiento con corticoesteroides en pulsos, tratamiento con corticoesteroides en pulsos más ciclosporina A o tratamiento con corticoesteroides más ciclofosfamida a dosis bajas. Al considerar los posibles efectos adversos significativos del tratamiento con inmunosupresores, sugirieron que, cuando no haya insuficiencia respiratoria, el tratamiento de primera línea para este tipo de pacientes debe ser la administración de corticoesteroides. ${ }^{6}$

Mientras la paciente recibía corticoesteroides por vía oral por compromiso renal, presentó dificultad respiratoria secundaria a la hemorragia pulmonar. La ciclofosfamida oral se interrumpió debido a que la paciente tuvo leucocitopenia. Por lo tanto, se optó por administrarle un tratamiento de MP en pulsos, y la paciente respondió bien en un período muy breve.

En un metanálisis publicado en 2013, la edad promedio de 36 pacientes con PSH que presentaron HAD fue de 16,5 años, la prevalencia fue del $0,8 \%$ al $5 \%$, y el $95 \%$ tenía compromiso renal. En pacientes con hemorragia alveolar, la incidencia de infiltrados pulmonares fue del 94\%, la incidencia de niveles reducidos de hemoglobina fue del $74 \%$ y la tasa de mortalidad fue del $28 \%{ }^{2}$

La HAD es una complicación potencialmente mortal de la PSH, y el diagnóstico y el tratamiento tempranos salvan vidas. Los síntomas pulmonares, la anemia y los infiltrados en la radiografía de tórax en pacientes con púrpura de Schönlein-Henoch deben considerar la HAD como posibilidad diagnóstica.

\section{REFERENCIAS}

1. Ozen S, Pistorio A, Iusan SM, Bakkaloglu A, et al. EULAR/ PRINTO/PRES criteria for Henoch-Schönlein purpura, childhood polyarteritis nodosa, childhood Wegener granulomatosis and childhood Takayasu arteritis: Ankara 2008. Part II: Final classification criteria. Ann Rheum Dis 2010;69(5):798-806.

2. Rajagopala S, Shobha V, Devaraj U, D'Souza G, et al. Pulmonary hemorrhage in Henoch-Schönlein purpura: case report and systematic review of the english literature. Semin Arthritis Rheum 2013;42(4):391-400.

3. Cazzato S, Bernardi F, Cinti C, Tassinari D, et al. Pulmonary function abnormalities in children with Henoch-Schönlein purpura. Eur Respir J 1999;13(3):597-601.

4. Castañer E, Alguersuari A, Andreu M, Gallardo X, et al. Imaging findings in pulmonary vasculitis. Semin Ultrasound CT MR 2012;33(6):567-79.

5. Al-Harbi NN. Henoch-Schönlein nephritis complicated with pulmonary hemorrhage but treated successfully. Pediatr Nephrol 2002;17(9):762-4.

6. Chen SY, Chang KC, Yu MC, Asueh S, et al. Pulmonary hemorrhage associated with Henoch-Schönlein purpura in pediatric patients: case report and review of the literature. Semin Arthritis Rheum 2011;41(2):305-12.

7. Usui K, Ochiai T, Muto R, Abe I, et al. Diffuse pulmonary hemorrhage as a fatal complication of Schönlein-Henoch purpura. J Dermatol 2007;34(10):705-8.

8. Matsubayashi R, Matsubayashi T, Fujita N, Yokota T, et al. Pulmonary hemorrhage associated with Henoch-Schönlein purpura in a child. Clin Rheumatol 2008;27(6):803-5. 